\title{
Mapeamento do processo produtivo e construtivo de alvenaria de tijolo de solo-cimento para habitação de interesse social
}

\section{Soil-cement masonry brick production and construction process mapping for social interest housing}

Camila Augusto Euphrosino ${ }^{1}$, Lia Lorena Pimentel ${ }^{2}$, Gladis Camarini ${ }^{3}$,Yuri Vilas Boas Ortigara ${ }^{4}$, Phelipe Viana Ruiz ${ }^{3}$, Patrícia Stella Pucharelli Fontanini ${ }^{3}$

\footnotetext{
${ }^{1}$ Faculdade de Engenharia Civil, Arquitetura e Urbanismo - UNICAMP - Rua Saturnino de Brito, 224, Cidade Universitária, CEP: 13083-889, Campinas, SP, Brasil.

e-mail: ceuphrosino@gmail.com

${ }^{2}$ Faculdade de Engenharia Civil - PUC-Campinas - Rodovia D. Pedro I, Km 136, Parque das Universidades, CEP: 13086-900, Campinas, SP, Brasil.

e-mail: lialorenapimentel@gmail.com

${ }^{3}$ Departamento de Arquitetura e Construção - UNICAMP - Rua Saturnino de Brito, 224, Cidade Universitária, CEP: 13083-889, Campinas, SP, Brasil.

e-mail: gcamarini@gmail.com, pspucha@gmail.com, phelipevruiz@ gmail.com

${ }^{4}$ IFSULDEMINAS - campus Pouso Alegre - Avenida Maria da Conceição Santos, 900, Parque Real, CEP 37550-000, Pouso Alegre, MG, Brasil.

e-mail: yuri.ortigara@ ifsuldeminas.edu.br
}

\section{RESUMO}

O assunto sustentabilidade vem crescendo cada vez mais, junto com a necessidade de redução de emissão de gás carbônico por todo o mundo. De modo que projetos, técnicas, e materiais que não prejudiquem o meio ambiente estão ganhando espaço nas pesquisas e nos mercados. Esse trabalho tem como objetivo principal um estudo de caso do processo produtivo e construtivo com tijolo solo-cimento, mais conhecido como tijolo ecológico, de uma HIS (Habitação de Interesse Social) na cidade de Limeira-SP. Para isso foram-realizados o mapeamento do processo produtivo dos tijolos, os quais são produzidos pelo próprio mutuário na olaria da prefeitura, e o mapeamento da construção da alvenaria em obra. Foram abordados conceitos Lean, tais como: Lean Construction e Mapeamento de Fluxo de Valor (MFV). Os resultados encontrados foram satisfatórios, de modo que se propôs uma diminuição no tempo de produção dos tijolos solo-cimento em quase $50 \%$, usando a ferramenta mapeamento de fluxo de valor. Foi possível diminuir em dois dias o tempo de construção da alvenaria de tijolo solo-cimento para uma residência de aproximadamente $50 \mathrm{~m}^{2}$, apenas introduzindo atividades em paralelo e utilizando a mão de obra de maneira mais eficiente.

Palavras-chave: Tijolo solo-cimento, Lean Thinking, Mapeamento de fluxo de valor, Habitação de Interesse Social.

\begin{abstract}
Sustainability issue is growing more and more, along with the need to reduce the emission of carbon dioxide around the world. So, projects, techniques and materials that don't harm the environment are gaining ground in research and markets. This work has as main objective a case study of the production and construction process of soil-cement brick, better known as ecological brick, of a SIH (Social Interest Housing) in the city of Limeira-SP. Other pertinent objectives of this research are the mapping of the productive process of the bricks, which are produced by the borrower himself in the brick factory, and the material flow mapping on construction. For this, Lean concepts will be addressed such as: Lean construction and value flow mapping
\end{abstract}


(VSM) will be addressed. The results were satisfactory, so that a reduction without time of production in the ecological pottery of the soil-cement bricks is proposed in almost $50 \%$, using value-flow mapping. It was possible to reduce in two days the time of construction of masonry of soil-cement brick to a residence of approximately $50 \mathrm{~m} 2$, only to introduce activities in parallel and to use a labor with more efficient way.

Keywords: Soil-cement brick, Lean Thinking, Value Stream Mapping, Housing of Social Interest

\section{INTRODUÇÃO}

O Brasil se encontra com um déficit habitacional de aproximadamente 6 milhões de moradias, sendo o estado de São Paulo o que mais contribui para esse déficit chegando a mais de 1 milhão de moradias [1]. Apesar de já existirem programas de habitação social por todo o país, e no estado de São Paulo, como Minha Casa Minha Vida, Casa Paulista, CDHU (Companhia Paulista de Desenvolvimento Habitacional), e parcerias público privadas. Estas iniciativas não são suficientes, portanto, ainda há a necessidade de implementar e criar novas formas para combater o problema habitacional brasileiro. Neste contexto, a Lei Federal 11.888 [2], assegura às famílias de baixa renda assistência técnica pública e gratuita para o projeto e a construção de habitação de interesse social.

A SEHAB (Secretaria de Habitação) de Limeira, visando cumprir o estabelecido pela Lei 11.888 e diminuir o déficit atual no município, implantou um programa que engloba a realização do projeto arquitetônico, projetos complementares, aprovação do projeto legal, orçamento e acompanhamento da obra. Além disso, outros serviços também são ofertados, como a doação de materiais a partir do Banco de Materiais, a produção de tijolos solo-cimento por meio da olaria ecológica que se situa na FAMUL (Fábrica de urbanos Mobiliário Urbano de Limeira), e a ajuda de mão de obra, através do Centro de Ressocialição de Limeira, que a partir de um convênio firmado com a FUNAP (Fundação Dr. Manuel Pedro Pimentel), fornece trabalhadores apenados que necessitam cumprir trabalhos para a sociedade.

A assistência técnica prestada às famílias carentes era feita por arquitetos e engenheiros da SEHAB, com a adoção de técnicas de construções com tijolos ecológicos, em que os próprios beneficiários produziam seus tijolos e participavam da execução da obra. Por ser um sistema implantado recentemente, foram identificadas muitas falhas de gestão, tanto no processo produtivo dos tijolos, como na organização de entrega de materiais nas obras. Esses problemas acarretavam na diminuição da produtividade atrasando as construções, e consequentemente o programa acaba atendendo menos famílias do que o sistema realmente suporta.

Assim, os objetivos desse trabalho foram verificar a eficácia da aplicação do pensamento Lean e de suas ferramentas, como o Mapeamento de Fluxo de Valor (MFV), e de fluxos dos materiais de construção, tanto no processo produtivo dos tijolos ecológicos quanto na construção de elementos de alvenaria em obras. O pensamento enxuto (Lean Thinking) nasceu juntamente com a necessidade de desenvolvimento da indústria automobilística. Segundo Womack, Jones e Roos [3], essa indústria teve início com o sistema artesanal em 1887 com a renomada fábrica de máquinas-ferramentas de Panhard e Levassor, na Europa. Os automóveis tinham sua produção individualizada para cada cliente e mesmo se fossem projetos iguais, a máquina final não sairia a mesma devido ao uso de ferramentas rudimentares, de uso geral e à falta de padrão de qualidade. A força de trabalho era altamente qualificada com baixo volume de produção. Devido à fabricação individualizada o custo era muito alto e não diminuía com o aumento do volume da produção.

Desse modo, no início do século XX, Henry Ford deu início à produção em massa, com intuito de superar os problemas inerentes à produção artesanal. Máquinas especializadas em uma única tarefa foram introduzidas no sistema de fabricação. Os projetos eram feitos por profissionais excessivamente especializados, mas os trabalhadores eram semi ou não qualificados. Consequentemente, os produtos eram padronizados e feitos em enormes volumes com grandes estoques, o que reduziu o preço para o consumidor, mas também diminuiu a variedade final, pois sair do modelo padrão de produção custava muito caro e os métodos de trabalho eram considerados monótonos [3].

Nos anos 70, os sistemas europeus e norte-americanos de produção em massa começaram a entrar em crise devido aos salários crescentes e às jornadas de trabalho em constante diminuição. Com essa situação, iniciou-se o crescimento de uma maneira inteiramente nova de se produzir a qual os japoneses tinham desenvolvido que nós chamamos de produção enxuta [3].

O surgimento da produção enxuta (Lean Production) se deu nas fábricas da Toyota, no Japão, após o término da Segunda Guerra Mundial. O engenheiro de produção, Taiichi Ohno, visto que a economia em seu país estava devastada pela guerra, buscou meios de tentar se reerguer e encontrou uma forma que combinava vantagens da produção artesanal e em massa. O produto final era voltado para o que o consumidor desejava, 
porém com baixos custos e larga escala de produção. Desse modo, era necessário o emprego de trabalhadores multiqualificados em todos os níveis da fabricação, com máquinas mais flexíveis e automatizadas, que produziam grandes volumes em ampla variedade [3].

A produção enxuta baseia-se nos princípios Lean Thinking, segundo Womack e Jones [4], que abordaram a questão de eliminação de desperdícios nas empresas pela aplicação do pensamento enxuto. Esses desperdícios são atividades que não agregam valor ao produto, mas se encontram na cadeia de produção. OHNO [5] descreveu os sete tipos de desperdícios possíveis de serem encontrados dentro da produção. São eles: excesso de produção, movimento, transporte, estoque, espera, atividades desnecessárias e defeitos. A construção civil realizava tradicionalmente um sistema de produção irracional, com grande índice de perdas e um alto custo de produção. Ainda hoje, a construção é um empreendimento muito complexo, que depende de diversos fatores, como a qualidade dos materiais e da mão de obra, e dos recursos disponíveis, fatores estes que quando não controlados causam desperdícios. Estas perdas podem ter origens diversas, seja em projetos mal concebidos, no uso de princípios obsoletos para o desenvolvimento do planejamento, ou até mesmo na predominância da individualidade de ações no canteiro, que impede a transparência do processo.

O Lean Construction ou Construção Enxuta, surgiu com o trabalho do pesquisador Finlandês Lauri Koskela, em 1992, como uma inovação para reverter este cenário. O esforço para sua implantação na construção se iniciou por parte do meio acadêmico, porém já há muitas empresas o colocando em prática em seus processos, visando a aprimorar seus níveis de desempenho e qualidade, ganhando assim destaque no mercado. O desafio da Construção Enxuta é tornar a empresa mais adaptável às mudanças de demanda e eliminar atividades e processos que não agregam valor, reduzindo assim os custos, gerando maior lucro e aumento da produtividade [6].

A ferramenta mais usada na construção civil é o mapeamento de fluxo de valor que é a elaboração de um "mapa" que mostra todo o fluxo de materiais e/ou informações, tendo início na distribuição de suprimentos pelos fornecedores, passando pela empresa e finalizando no cliente. Pela análise do mapa de fluxo de valor identificam-se atrasos no processo produtivo, entendendo quais são as etapas que agregam ou retiram valor do produto. Desse modo, melhorias podem ser estudadas e propostas, sendo possível a aplicação de ferramentas para redução de desperdícios e aumento da eficiência produtiva [7].

Vários autores têm desenvolvido trabalhos e pesquisas usando a ferramenta de MFV para estudos de caso [8,9,10,11]. FONTANINI e PICCHI [8] fizeram um estudo de caso do fluxo de projetos em um conjunto habitacional de Itatiba, com uso da ferramenta Lean de mapeamento de fluxo de valor administrativo. Nesse trabalho foi feito o mapa atual e foram encontrados desperdícios como retrabalho e filas de processos acumulados os quais impactavam no Lead Time total da execução de projeto atrasando assim a execução da obra. Desse modo, foram identificadas possíveis melhorias no fluxo de valor.

TOMMELEIN e LI [9] abordaram como estudo de caso a cadeia de suprimentos de concreto para a construção, com a aplicação da ferramenta just-in-time. Para estudar o sistema logístico foi feito um mapeamento do fluxo de suprimentos, distinguindo o sistema tradicional do sistema de processo Lean. CHILDERHOUSE et al. [10] estudaram estratégias para o fluxo de suprimentos da cadeia de fornecimento conforme qualquer tipo de necessidade do cliente, para a construção de edifícios. Foi feito um estudo de caso no Reino Unido, com a ferramenta de Mapeamento de fluxo de valor.

POLAT e BALLARD [11] trabalharam com o mapeamento de fluxo de suprimentos de aço para a execução de concreto armado em construções na Turquia. O mapeamento foi feito junto com visitas as empresas envolvidas na cadeia de fornecimento e entrevistas com agentes participantes do processo. No estudo de caso foram constatados 5 tipos diferentes de configurações da cadeia de fornecimento. Um número significativo de problemas foi identificado, resultantes de transferências de dados imprecisos entre os agentes participantes, e, portanto, de atrasos e interrupções no fluxo de informações. Dessa maneira, foram descritas recomendações e propostas melhorias do desempenho.

Nessas pesquisas, pode-se visualizar que em toda área em que há o desenvolvimento de um produto, o desperdício de tempo, de custo, e problemas com fluxo de informação, são frequentes. Com a ferramenta Lean de MFV é possível identificar esses desperdícios e propor mudanças, gerando benefícios. PICCHI [12] procurou identificar as oportunidades de aplicação do Lean Thinking e suas ferramentas na área de construção, englobando todas as etapas e fluxos como negócios, projeto, obra, suprimentos, uso e manutenção. Desse modo, o autor conclui que apesar das diferenças da área de manufatura e construção, há várias discussões e casos relacionados ao fluxo de projetos, suprimentos e obras com aplicações de ferramentas baseadas nos princípios de fluxo. Os fluxos de negócios, uso e manutenção ainda não receberam muita atenção de pesquisadores e profissionais da área [12].

PÉREZ et al.[13], estudaram as perdas ocasionadas durante os processos de transporte nas atividades 
da construção civil, identificando os principais eventos que geram estas perdas bem como as consequências destas perdas. Neste mesmo estudo os autores propõem uma classificação para os tipos de perdas de transporte e sugerem a aplicação de princípios Lean como alternativa para combater estas perdas.

Os princípios Lean têm sido estudados para diversas aplicações em vários setores da construção civil. Este estudo traz as contribuições decorrentes da aplicação destes princípios no processo produtivo de tijolos solo-cimentos e na construção de elementos de alvenaria com estes tijolos.

\section{MATERIAIS E MÉTODOS}

A pesquisa foi baseada em um estudo de caso de uma construção residencial de uma HIS (Habitação de Interesse Social) pelo programa de assistência técnica da SEHAB Limeira-SP, juntamente com auxilio e estudo da produção da olaria ecológica da cidade. Foi realizado o MFV para a produção de tijolos na olaria e para a construção de alvenaria em obra. A análise de desperdícios e recomendações para o mapeamento foi realizada por meio dos métodos citados por ROTHER e SHOOK [7]. Para o MFV na produção de tijolos na olaria e no recebimento desses e confecção de alvenaria em obra, foram reproduzidas a planta baixa da obra a ser realizada e o layout da FAMUL, os quais são apresentados nas figuras 1 e 2 a seguir. Foi escolhido o projeto de planta baixa de uma residência de dois quartos por ser o mais requisitado pelos atendidos da SEHAB. 


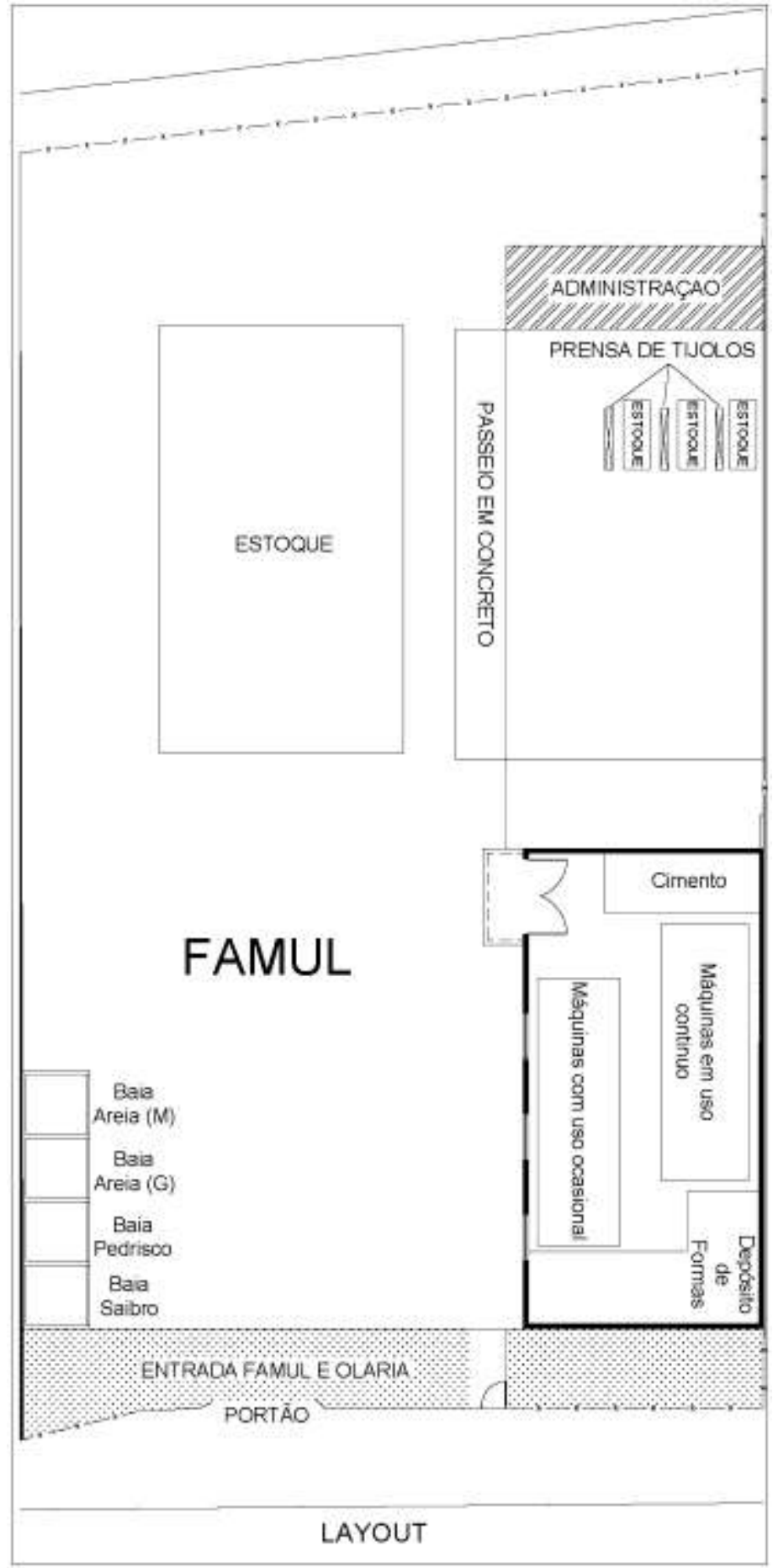

Figura 1: Layout FAMUL. 


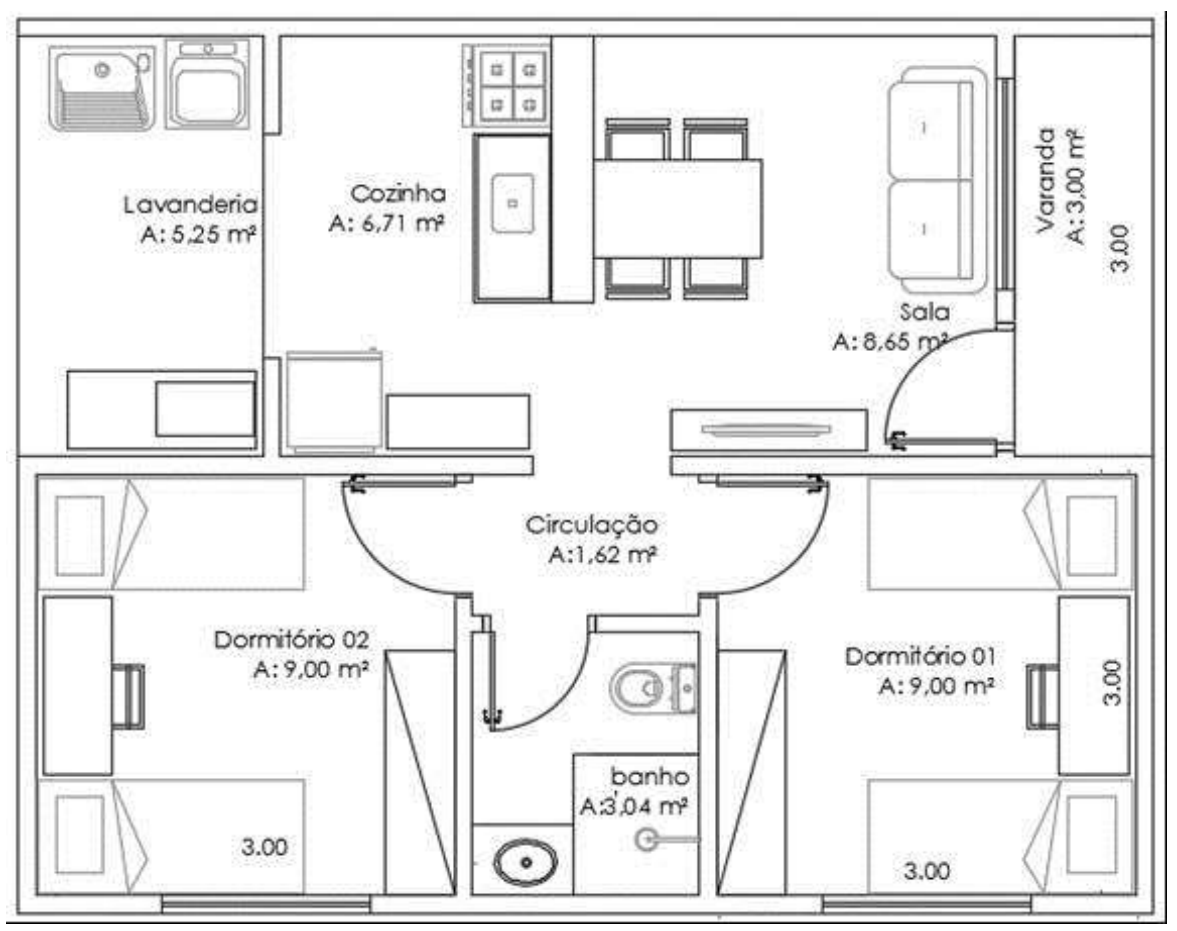

Figura 2: Planta baixa residencial de dois quartos. Fonte: Autoria própria.

Após o levantamento de dados, foram desenhados os mapas de fluxo de valor do estado atual, tanto do processo de produção dos tijolos na olaria, como do processo de construção da alvenaria. Foram detectados dois agentes participantes importantes do processo: o engenheiro responsável pela entrega de materiais em obra e o engenheiro responsável pela fiscalização da produção do tijolo solo-cimento na olaria ecológica. As entrevistas foram realizadas para se compreender o fluxo correto de materiais e informações, e possibilitar a elaboração do desenho do mapa de estado atual. Por fim, foram identificados os desperdícios por meio do estudo do mapa de estado atual e elaboradas propostas apresentadas nos mapas do estado futuro, visando a diminuição do tempo total de produção e de execução da habitação.

\section{RESULTADOS E DISCUSSÃO}

Inicialmente são apresentados o levantamento relativo ao processo de dos tijolos e a proposta de alteração de layout e forma de trabalho visando o aumento da capacidade produtiva da olaria.

\subsection{Mapeamento de fluxo de valor inicial da olaria ecológica}

Por meio de visitas técnicas a olaria ecológica observou-se todo o processo de produção do tijolo, sendo relatado em imagens conforme a Figura 3. Foi realizada também uma entrevista com o engenheiro responsável pela fiscalização da produção na FAMUL a respeito da produtividade. As famílias podem utilizar a olaria duas vezes na semana, por um período de 4 h por dia, com produção média de 100 tijolos por dia. Com essas informações foi elaborado a organização semanal da olaria ecológica (Tabela 1), o mapa de fluxo de valor inicial da olaria ecológica (Figura 4), e o cronograma de produção da família (Figura 5).

O processo de fabricação do tijolo solo-cimento na olaria é composto por 8 etapas, as quais estão ilustradas na Figura 3: 

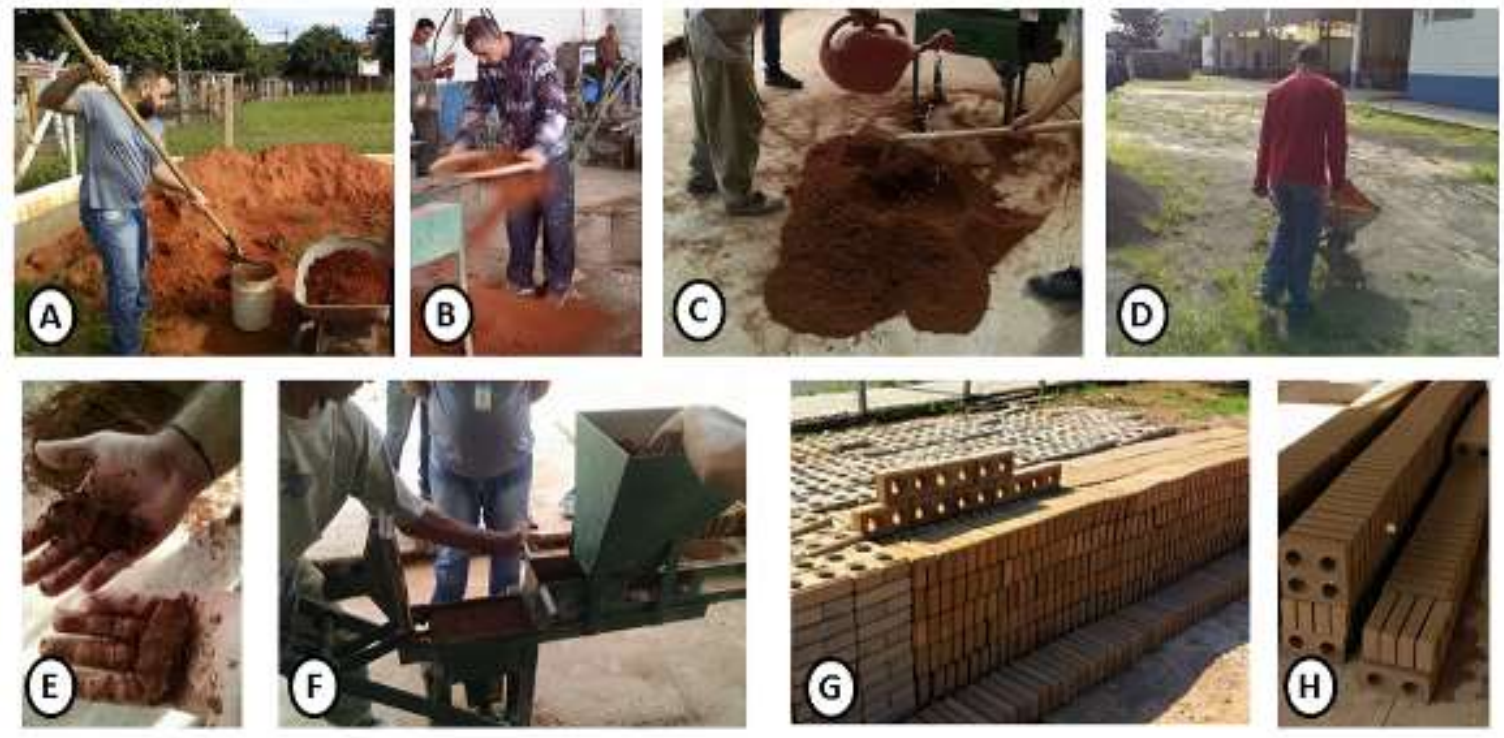

Figura 3: Processo de fabricação do tijolo de solo-cimento. (a): enchimento da carriola com 7 baldes de saibro na baia; (b): transporte do saibro ao local de produção por meio da carriola; (c): peneiramento manual do saibro; (d): mistura manual do saibro, cimento e água; (e): teste empírico do ponto da mistura; (f): transferência da mistura para a máquina e prensagem manual; (g): estocagem dos tijolos prontos em local coberto por 7 dias para o processo de cura; (h): estocagem dos tijolos em local aberto até serem levados para obra.

A Tabela 1 mostra a distribuição semanal das famílias na utilização da olaria ecológica. Apenas 4 famílias participam simultaneamente do programa na olaria ecológica até o término de sua produção necessária para construção da residência. Além disso, o espaço da FAMUL destinado a produção de tijolos pode ser usado apenas de segunda a quinta feira, no período de 08:00 às 12:00 h e 14:00 às 18:00 h. Após sexta feira o espaço é utilizado para outras produções de móveis urbanos da cidade.

Tabela 1: Distribuição semanal das famílias para a utilização da olaria

\begin{tabular}{l|l|l|l|l}
\hline Horário/ Dia & Segunda & Terça & Quarta & Quinta \\
\hline 08:00 as 12:00 h & Família 1 & Família 3 & Família 1 & Família 3 \\
\hline 14:00 as 18:00 h & Família 2 & Família 4 & Família 2 & Família 4 \\
\hline
\end{tabular}

Observou-se que cada família possui 8 horas de trabalho por semana, e apenas uma pessoa da família costuma participar da produção. O projeto representado na Figura 2, escolhido para o mapeamento do trabalho, necessita de aproximadamente 8000 tijolos, sendo $10 \%$ blocos canaletas, $10 \%$ meio blocos e $80 \%$ blocos inteiros. Com essas informações foi possível elaborar o mapeamento de fluxo de valor inicial da olaria ecológica, conforme apresentado na Figura 4. Foram levantados os tempos de produção para um homem produzir cada conjunto de blocos, conforme Equações 1 a 3, em função do tipo de bloco.

$$
[6400 \text { blocos inteiros } / 25 \text { blocos inteiros } / \mathrm{h}] / 8 \mathrm{~h} / \text { semana }=32 \text { semanas }(1)
$$

Meios blocos:

$$
[1600 \text { meios blocos } / 31 \text { meios blocoss } / h] / 8 h / \text { semana }=6,5 \text { semanas }(2)
$$

Blocos canaletas:

$$
\text { [800 blocos canaletas } / 31 \text { blocos canaletas } / h] / 8 h / \text { semana }=6 \text { semanas (3) }
$$




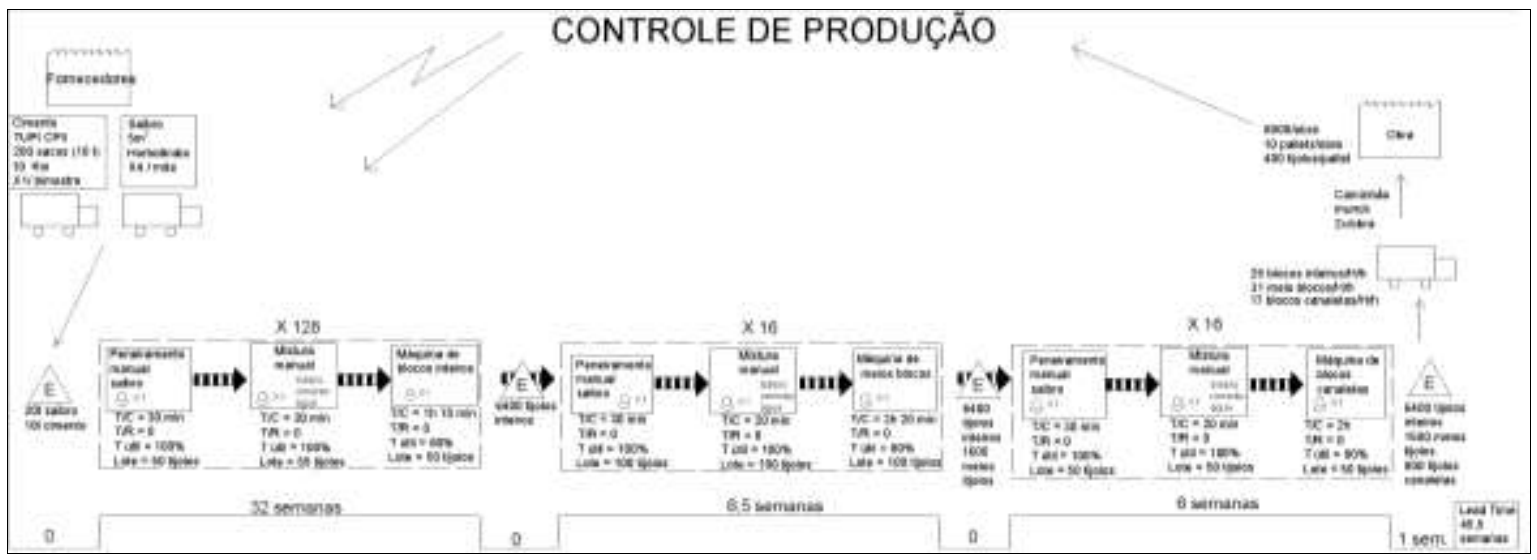

Figura 4: MFV inicial da olaria ecológica.

Assim o tempo total de produção dos tijolos para uma obra é 44,5 semanas + 1 semana (Tempo de cura), ou seja, 45,5 semanas. Com estes dados construiu-se o cronograma de produção (Figura 5) para famílias que optam pelo projeto de residência com dois dormitórios.

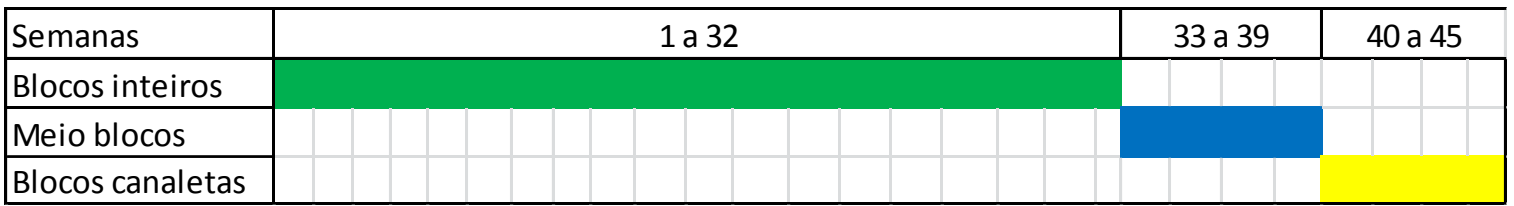

Figura 5: Cronograma de produção atual.

\subsection{Mapeamento do fluxo de valor proposto para olaria ecológica}

Ao longo do desenvolvimento da pesquisa, ferramentas e novas técnicas foram incorporadas ao sistema com objetivo de otimizar o tempo de produção e aumentar a qualidade do tijolo, ou seja, algumas das mudanças propostas no mapeamento de fluxo de valor futuro da olaria ecológica já estão sendo utilizadas na produção.

Primeiramente, foi proposta e realizada uma mudança no Layout da FAMUL, de modo que a baia de armazenamento do saibro se tornou maior e muito mais próxima da área de produção, diminuindo a distância e o tempo de transporte do solo (Kaizen 1). Além disso, as máquinas de prensar os tijolos foram dispostas de uma maneira que permitisse uma melhor e maior movimentação de materiais e pessoas dentro do galpão (Kaizen 2), conforme mostra a Figura 6.

Novas ferramentas foram introduzidas na produção como a peneira elétrica que reduz muito o tempo de peneiramento do saibro, e a betoneira no auxílio da mistura do saibro, cimento e água. Com o intuito de aumentar a qualidade do produto, os tijolos deixaram de ser armazenados diretamente no chão, passando a serem armazenados sobre pallets. Durante o período de cura, os tijolos são cobertos por uma lona plástica evitando a perda de água para o ambiente. 


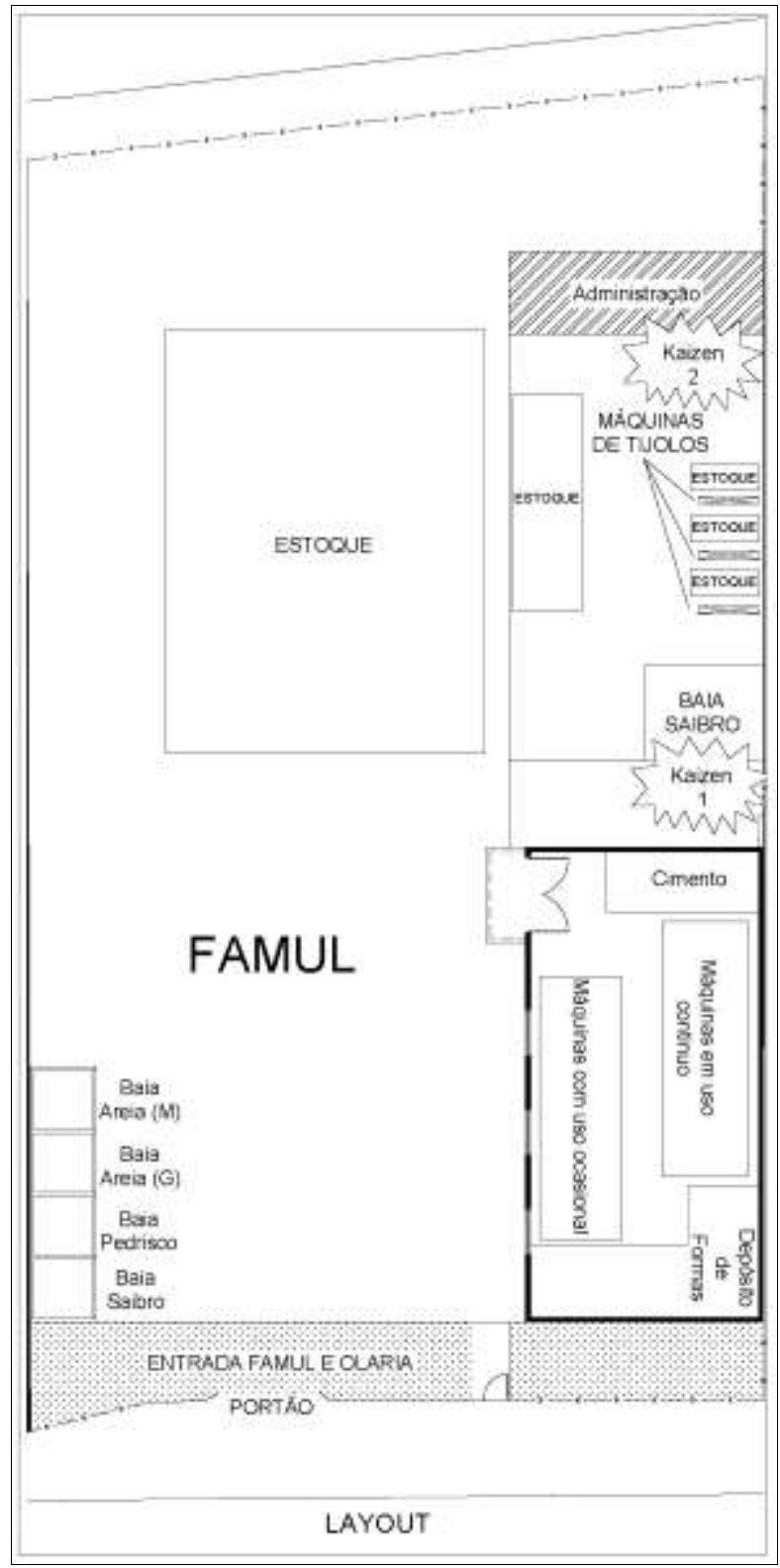

Figura 6: Layout proposto da FAMUL ecológica.

Outra medida que pode ser tomada para otimização da produção e que ainda não foi incorporada ao processo é a adoção do trabalho simultâneo de duas famílias. Observou-se que a fábrica possui três maquinas manuais para prensagem de tijolos ( 1 de tijolo inteiro, 1 de blocos canaletas e outra de meio bloco) e que não há nenhum obstáculo para duas famílias trabalharem no mesmo espaço simultaneamente: uma utilizando a máquina de tijolos inteiros e a outra utilizando a de meio-bloco ou canaletas. Assim, foi proposta uma nova distribuição semanal da utilização da olaria pelas famílias, conforme a Tabela 2, em que F=família.

Tabela 2: Proposta de distribuição semanal das famílias na utilização da olaria ecológica

\begin{tabular}{c|c|c|c|c}
\hline Horário/Dia & Segunda-Feira & Terça-Feira & Quarta-Feira & Quinta-Feira \\
\hline \multirow{2}{*}{ 08:00 AS 12:00h } & F1 - Bloco inteiro & F3 - Bloco inteiro & F1 - Bloco inteiro & F3 - Bloco inteiro \\
\cline { 2 - 5 } & F3 - Bloco canaleta & F1 - Bloco canaleta & F3 - Meio bloco & F1 - Meio bloco \\
\hline \multirow{2}{*}{ 14:00 AS 16:00h } & F2 - Bloco inteiro & F4 - Bloco inteiro & F2 - Bloco inteiro & F4 - Bloco inteiro \\
\cline { 2 - 5 } & F4 - Bloco canaleta & F2 - Bloco canaleta & F4 - Meio bloco & F2 - Meio bloco \\
\hline
\end{tabular}

Dessa forma, cada família teria 8h/semana para produção de blocos inteiros, 4h/semana para meios 
blocos e 4h/semana para blocos canaletas. Assim, pode-se representar o mapeamento de fluxo de valor proposto da olaria ecológica como mostra a Figura 7.

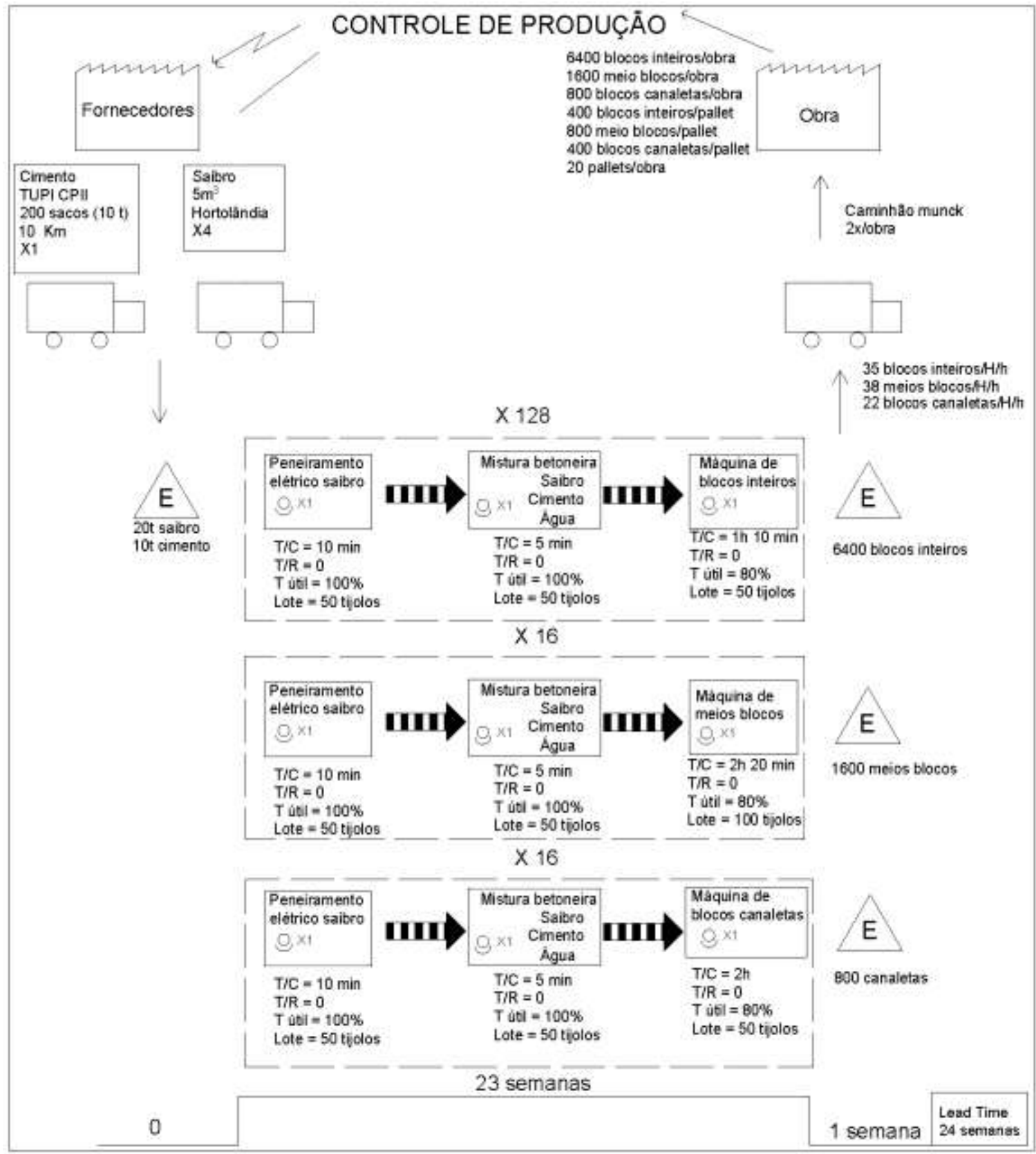

Figura 7: MFV proposto para olaria ecológica.

As Equações 4 a 6 indicam o cálculo dos tempos de produção de um homem para cada conjunto de blocos.

Blocos inteiros:

$$
\left\{\frac{[6400 \text { blocos inteiros } \sqrt{35} \text { blocos inteiros } \text { hin }]}{8 \text { hisemana }}\right\}+1 \text { semana de cura }=24 \text { semanas }(4)
$$

Meios blocos:

$$
\left\{\frac{[1600 \text { melos blocos } / 38 \text { melos blocos } f h]}{4 h / \text { semana }}\right\}+1 \text { semana de cura }=11,5 \text { semanas }(5)
$$

Blocos canaletas: 
$\left\{\frac{[800 \text { blocos canaletas } f 17 \text { blocos canaletas } f h]}{4 h / \text { semana }}\right\}+1$ semana de cura $=10$ semanas

(6)

Assim, iniciando-se a fabricação dos meios blocos e dos blocos canaleta simultaneamente aos blocos inteiros, o tempo total de produção cairá para 24 semanas, conforme mostra o cronograma de produção (Figura 8).

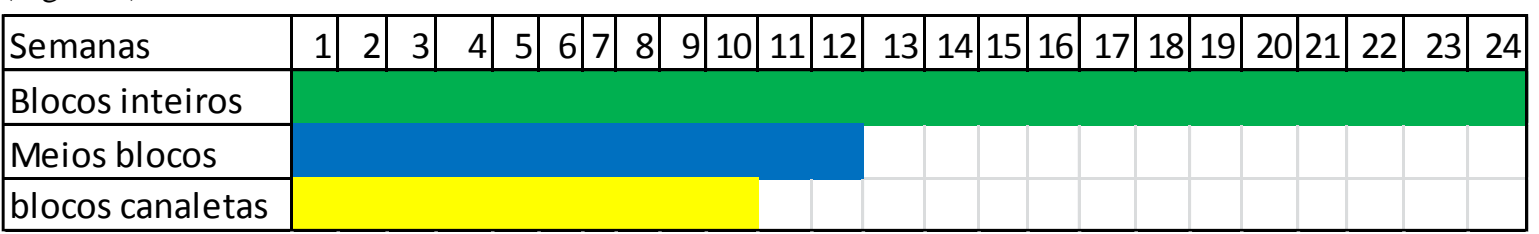

Figura 8: Cronograma de produção proposto.

Com as alterações propostas, o tempo de produção dos tijolos para uma residência de dois dormitórios caiu de 44,5 semanas para 24 semanas (Figura 9), o que representa uma diminuição de $46 \%$ do tempo inicial. Ressalta-se ainda, que as modificações na estocagem dos materiais melhoram a qualidade dos tijolos.

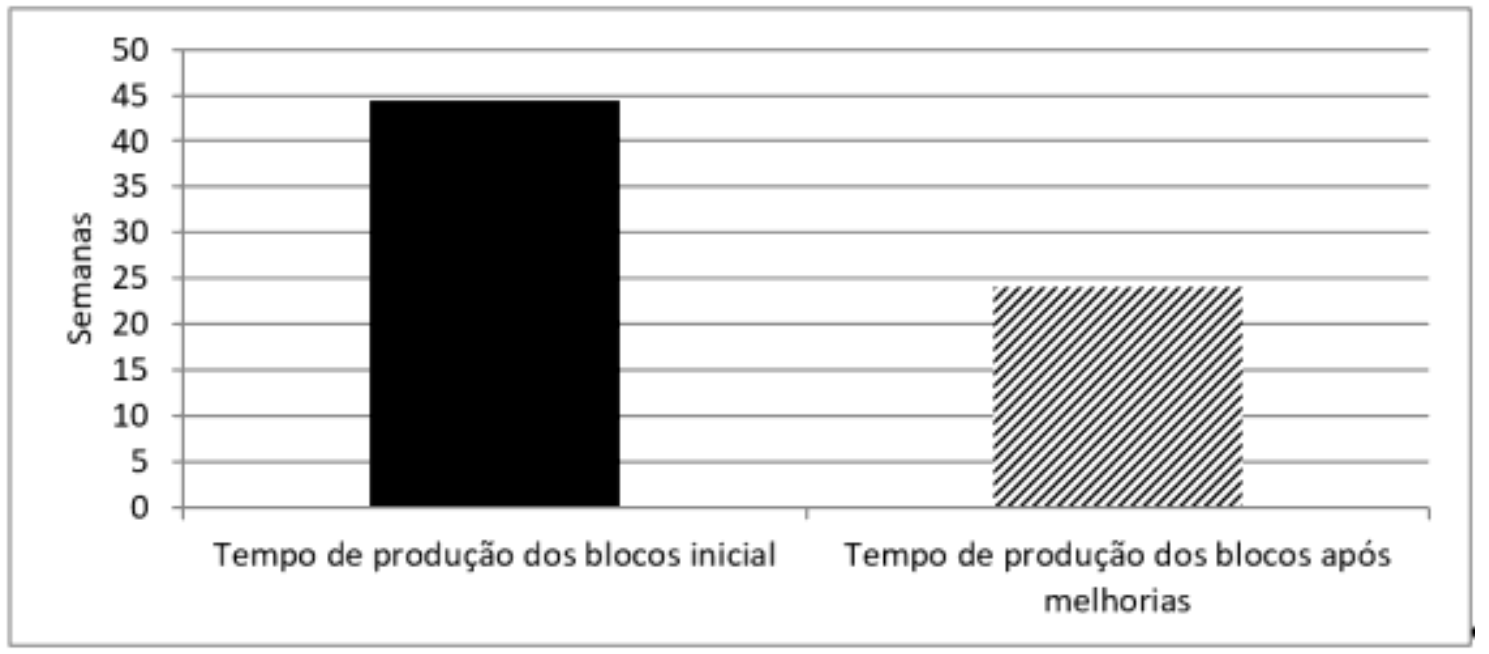

Figura 9: Tempo de produção dos tijolos em solo cimento antes e após melhorias.

\subsection{Mapeamento do fluxo de valor atual do recebimento dos materiais em obra e construção de uma alvenaria de tijolos solo-cimento}

Por meio de visitas técnicas nas obras de HIS com tijolo solo-cimento foi observado todo o processo de construção da alvenaria, composto por colocação de armação, elevação das fiadas, preparo e lançamento de concreto bem como o armazenamento dos materiais necessários para execução da alvenaria, conforme podese observar na Figura 10. Também foi realizada uma entrevista com o engenheiro responsável pelas obras sobre o processo de transporte dos tijolos da olaria à obra e obteve-se que o transporte é realizado em duas viagens de caminhão Munck, com 10 pallets, sendo que cada pallet contém 400 tijolos. Com essas informações foi elaborado o mapeamento de fluxo de valor atual do recebimento dos materiais em obra e construção de uma alvenaria de tijolos solo-cimento, apresentados na Figura 11.

Conforme pode ser observado na Figura 11 o tempo total para a construção de um metro de altura em toda a obra do projeto escolhido é de 36 h 30 min. Como a alvenaria total é composta por uma altura média de 3 metros, o tempo total de construção de toda alvenaria da obra é $109 \mathrm{~h} 30 \mathrm{~min}$, o que em uma jornada de trabalho de $8 \mathrm{~h} /$ dia são 14 dias. 

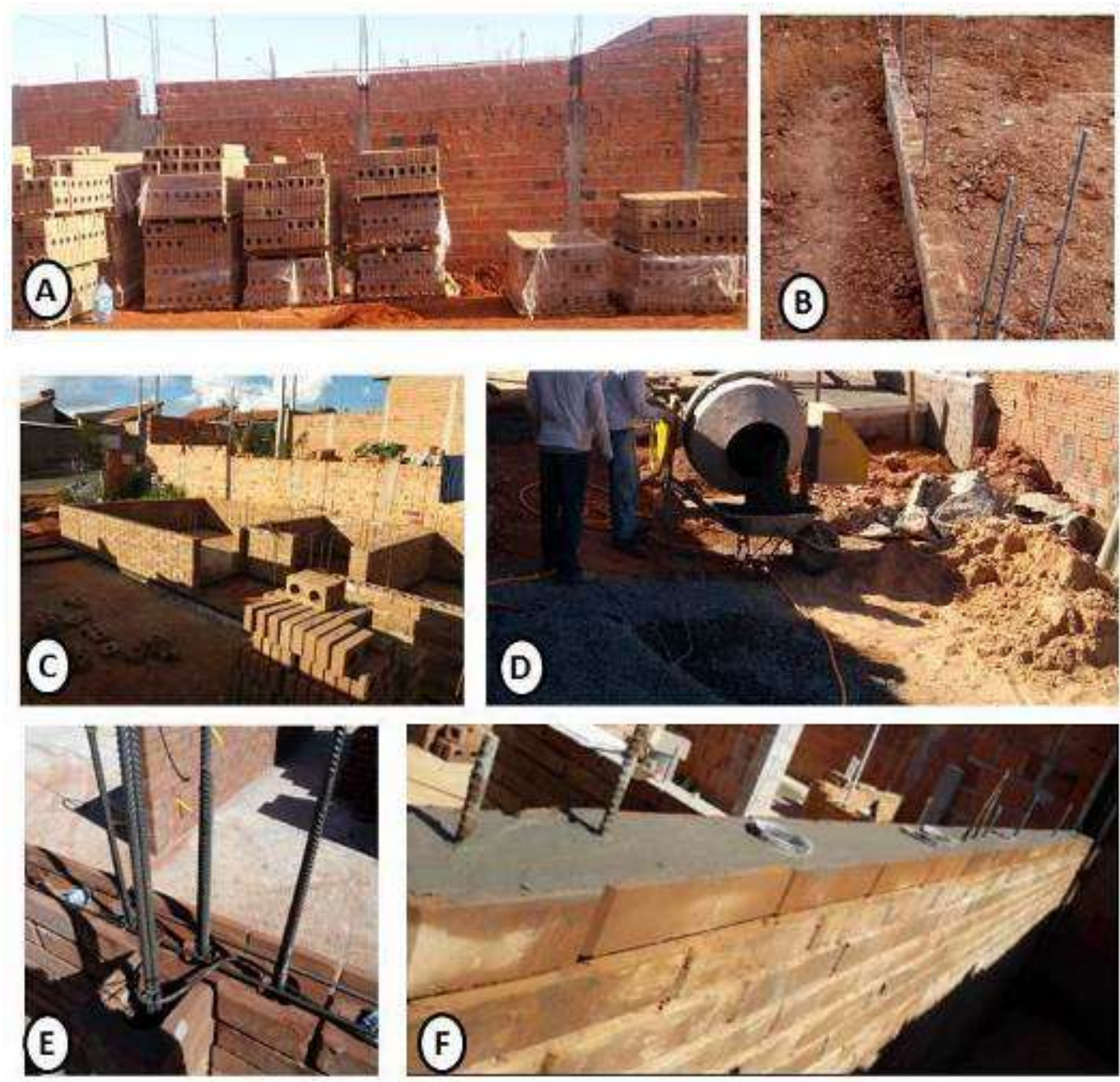

Figura 10: Etapas de produção da alvenaria com tijolo solo cimento. (a): estocagem dos tijolos na obra; (b): colocação da armação dos pontos de grauteamento; (c): elevação das fiadas; (d): produção do concreto; (e): colocação das armaduras nas canaletas; (f): concretagem das canaletas.

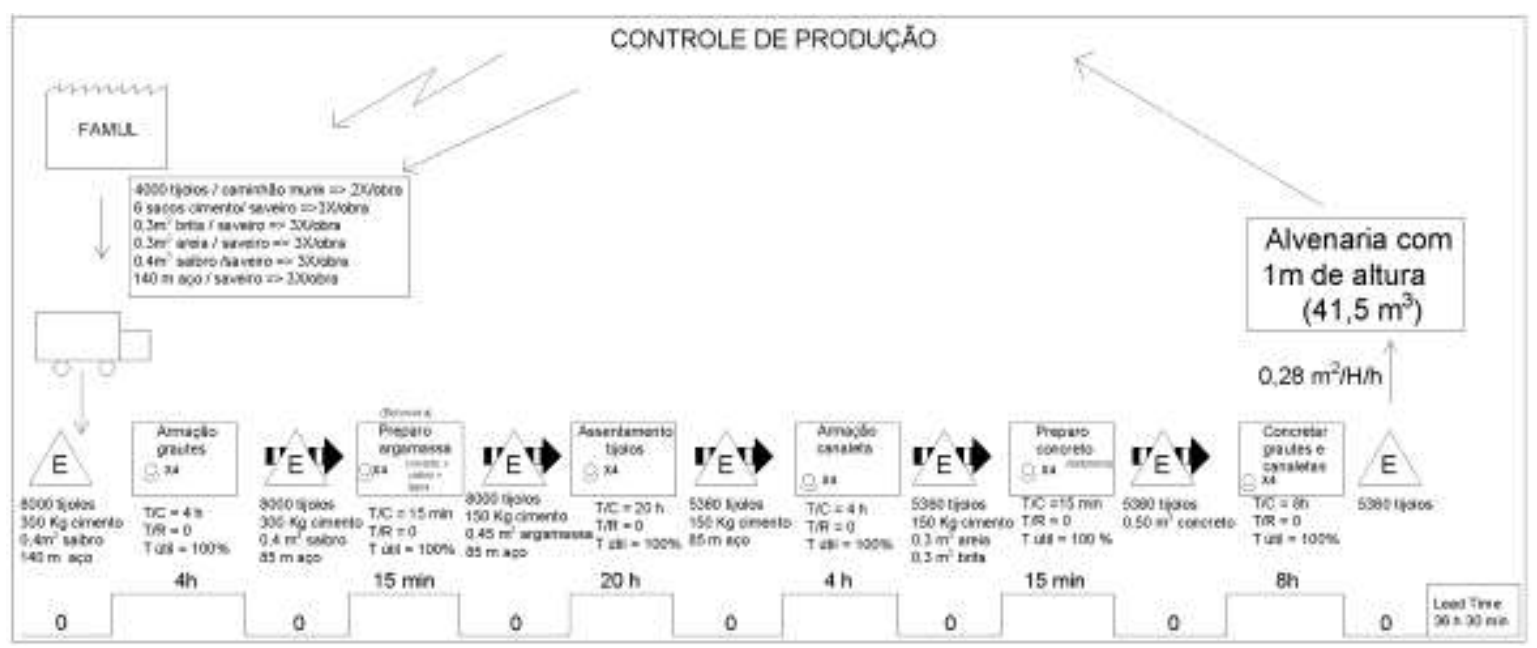

Figura 11: MFV atual de uma construção de uma alvenaria de tijolos solo-cimento. 


\subsection{Mapeamento do fluxo de valor proposto do recebimento dos materiais em obra e construção de uma alvenaria de tijolos solo-cimento}

Para o mapeamento de fluxo de valor proposto do recebimento dos materiais em obra e construção da alvenaria, foi proposto que algumas atividades fossem feitas em paralelo, conforme a Figura 12, já que se percebeu nas visitas a obra que alguns trabalhadores ficavam ociosos em certos períodos.

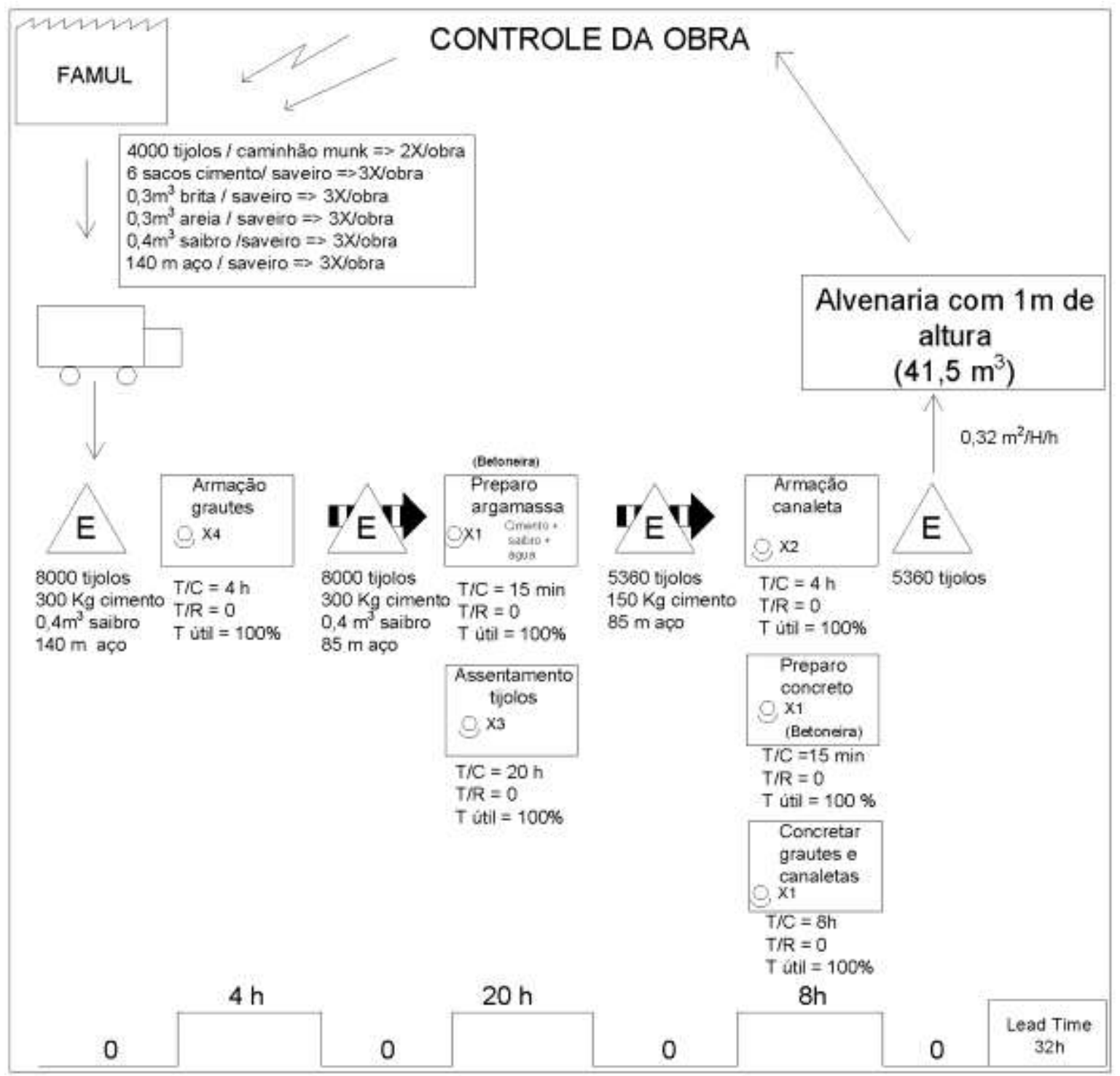

Figura 12: MFV proposto de uma construção de alvenaria de tijolos solo-cimento.

Dessa maneira, o tempo total de construção de um metro de alvenaria da obra caiu para 32 h. Logo, a produtividade aumentou de $0,28 \mathrm{~m}^{2} / \mathrm{H} / \mathrm{h}$ para $0,32 \mathrm{~m}^{2} / \mathrm{H} / \mathrm{h}$, e o tempo total de construção da alvenaria diminuiu para 96 h, o que em uma jornada de trabalho de 8h/dia são 12 dias. Portanto é possível completar a construção da alvenaria com dois dias a menos.

\section{CONCLUSÕES}

A aplicação do Lean Thinking, mais especificamente do mapeamento de fluxo de valor contribui para identificação de possibilidades de melhorias nos sistemas de produção de tijolos de solo-cimento, otimizando a produção, o espaço e a utilização das máquinas. Neste estudo de caso, após a proposição de um novo layout a redução do tempo de produção foi de $46 \%$.

Da mesma maneira, o mapeamento do fluxo de valor aplicado aos processos executivos de alvenaria de tijolos de solo cimento identifica e possibilita correções no processo, diminuindo o tempo necessário para execução das atividades. Neste estudo de caso, identificou-se a possibilidade da realização de atividades 
simultaneamente e obteve-se redução de $14,3 \%$ no tempo necessário para execução da alvenaria.

\section{AGRADECIMENTOS}

Os autores agradecem todos que de alguma maneira contribuíram para esta pesquisa, em especial a equipe da Secretaria de Habitação da Prefeitura de Limeira-SP que auxiliou e acompanhou o desenvolvimento do trabalho.

\section{BIBLIOGRAFIA}

[1] FUNDAÇÃO JOÃO PINHEIRO. Déficit Habitacional no Brasil 2013-2014, Belo Horizonte, 2016.

[2] BRASIL. Lei 11.888, de 24 de dezembro de 2008. Altera, atualiza e consolida a legislação sobre direitos autorais e dá outras providências, http://www.planalto.gov.br/ccivil_03/_Ato2007-

2010/2008/Lei/L11888.htm. Acessado em abril de 2017.

[3] WOMACK, J. P., JONES, D. T., ROOS, D. A máquina que mudou o mundo. Tradução de Ivo Korytovski. 15 ed., Rio de Janeiro, Campus, 1992.

[4] WOMACK, J. P., JONES, D. T. A Mentalidade Enxuta nas empresas: elimine o desperdício e crie riqueza, Tradução de Ana Beatriz Rodrigues e Priscilla Martins Celeste, 5 ed., Rio de Janeiro, Campus, 1998.

[5] OHNO, T. Just-in-time for Today and Tomorrow, Tradução por Joseph P. Schmelzeis. Productivity Press, 1988.

[6] FONTANINI P. S. P. "Mentalidade enxuta no fluxo de suprimentos da construção civil - aplicação de macro mapeamento na cadeia de fornecedores de esquadrias de alumínio", Tese de M.Sc., Universidade Estadual de Campinas, Campinas, SP, Brasil, 2004.

[7] ROTHER, M., SHOOK, J. Aprendendo a Enxergar, São Paulo, Lean Institute Brasil, 2000.

[8] FONTANINI, P. S. P., PICCHI, F. A. "Mapeamento administrativo de fluxo de valor em habitações de interesse social - Um estudo de caso - Fluxo de projeto do conjunto habitacional de Itatiba”, In: Encontro Nacional de Tecnologia do Ambiente Construído, Fortaleza, Ceará, Brasil, 7-10 outubro de 2008.

[9] TOMMELEIN, I.D., LI, A.E.Y. "Just-in-Time Concrete Delivery: Mapping Alternatives for Vertical Supply Chain Integration", In: 7th Annual Conference of the International Group for Lean Construction, pp. 97-108, Berkeley, USA, 26-28 Jul. 1999.

[10] CHILDERHOUSE, P., HONG-MINH, S. M., NAIM, M. M. "Selecting The Right Strategy To Meet Customer Requirements", In: 8th Annual Conference of the internacional Group for Lean Construction. Brigthon, UK, 17-19 Jul. 2000.

[11] POLAT, G., BALLARD, G. "Construction Supply Chains: Turkish Supply Chain Configurations for Cut and Bent Rebar", In: 11th Annual Conference of the International Group for Lean Construction. Virginia, USA, 14-16 Jul. 2003.

[12] PICCHI, F. A. "Oportunidades da aplicação do Lean Thinking na construção”, Revista Ambiente Construido, v.3, n.1, p.7-23, jan./mar. 2003.

[13] PÉREZ, C., COSTA, D., GONÇALVES, J. "Identificação, mensuração e caracterização das perdas por transportes em processos construtivos”, Revista Ambiente Construído, v.16, n.1, p.243-263, jan./mar. 2016.

\section{ORCID}

Camila Augusto Euphrosino

Yuri Vilas Boas Ortigara

Lia Lorena Pimentel

Patricia Stella Pucharelli Fontanini

Gladis Camarini

Phelipe Viana Ruiz https://orcid.org/0000-0002-7924-7414

https://orcid.org/0000-0002-0101-9155

https://orcid.org/0000-0001-5146-0451

https://orcid.org/0000-0002-7532-7505

https://orcid.org/0000-0003-4536-9699

https://orcid.org/0000-0003-3092-1276 